\title{
3'-UTR Polymorphisms of Vitamin B-Related Genes Are Associated with Osteoporosis and Osteoporotic Vertebral Compression Fractures (OVCFs) in Postmenopausal Women
}

\author{
Tae-Keun Ahn ${ }^{1,+} \mathbb{C}^{\circ}$, Jung Oh Kim ${ }^{2,+}{ }^{\oplus}$, Hui Jeong An ${ }^{3}$, Han Sung Park ${ }^{3}$, Un Yong Choi ${ }^{4}{ }^{(}$, \\ Seil Sohn ${ }^{4}$, Kyoung-Tae Kim ${ }^{5,6}{ }^{(D}$, Nam Keun Kim ${ }^{3}$ * and In-Bo Han ${ }^{4, *(D)}$ \\ 1 Department of Orthopedics, CHA Bundang Medical Center, CHA University, Seongnam 13496, Korea; \\ ajh329@gmail.com \\ 2 Theragen Bio Co., Ltd. 145, Gwanggyo-ro, Yeongtong-gu, Suwon 16229, Korea; jokim8505@gmail.com \\ 3 Department of Biomedical Science, College of Life Science, CHA University, Seongnam 13488, Korea; \\ tody2209@naver.com (H.J.A.); hahnsung@naver.com (H.S.P.) \\ 4 Department of Neurosurgery, CHA Bundang Medical Center, CHA University, Seongnam 13496, Korea; \\ nschoiuy@gmail.com (U.Y.C.); sisohn@cha.ac.kr (S.S.) \\ 5 Department of Neurosurgery, School of Medicine, Kyungpook National University, Daegu 41944, Korea; \\ nskimkt7@gmail.com \\ 6 Department of Neurosurgery, Kyungpook National University Hospital, Daegu 41944, Korea \\ * Correspondence: nkkim@cha.ac.kr (N.K.K.); hanib@cha.ac.kr (I.-B.H.); Tel.: +82-31-881-7137 (N.K.K.); \\ +82-31-780-1924 (I.-B.H.) \\ + The authors are contributed equally to this work.
}

Received: 2 April 2020; Accepted: 27 May 2020; Published: 2 June 2020

\begin{abstract}
As life expectancy increases, the prevalence of osteoporosis is increasing. In addition to vitamin D which is well established to have an association with osteoporosis, B vitamins, such as thiamine, folate (vitamin B9), and cobalamin (vitamin B12), could affect bone metabolism, bone quality, and fracture risk in humans by influencing homocysteine/folate metabolism. Despite the crucial role of $B$ vitamins in bone metabolism, there are few studies regarding associations between $B$ vitamin-related genes and osteoporosis. In this study, we investigated the genetic association of four single nucleotide polymorphisms (SNPs) within the 3'-untranslated regions of vitamin B-related genes, including TCN2 (encodes transcobalamin II), CD320 (encodes transcobalamin II receptor), SLC19A1 (encodes reduced folate carrier protein 1), and SLC19A2 (encodes thiamine carrier 1), with osteoporosis and osteoporotic vertebral compression fracture (OVCF). We recruited 301 postmenopausal women and performed genotyping of CD320 rs9426 C>T, TCN2 rs10418 C>T, SLC19A1 rs1051296 G>T, and SLC19A2 rs16862199 $C>T$ using a polymerization chain reaction-restriction fragment length polymorphism assay. There was a significantly higher incidence of both osteoporosis (AOR 5.019; 95\% CI, 1.533-16.430, $p<0.05$ ) and OVCF (AOR, 5.760; 95\% CI, 1.480-22.417, $p<0.05$ ) in individuals with genotype $C D 320 \mathrm{CT}+\mathrm{TT}$ and high homocysteine concentrations. Allele combination analysis revealed that two combinations, namely CD320 C-TCN2 T-SLC19A1 T-SLC19A2 C (OR, 3.244; 95\% CI, 1.478-7.120, $p<0.05$ ) and CD320 T-TCN2 C-SLC19A1 G-SLC19A2 C (OR, 2.287; 95\% CI, 1.094-4.782, $p<0.05)$, were significantly more frequent among the osteoporosis group. Our findings suggest that SNPs within the CD320 gene in 3'-UTR may contribute to osteoporosis and OVCF occurrences in some individuals. Furthermore, specific allele combinations of CD320, TCN2, SLC19A1, and SLC19A2 may contribute to increased susceptibility to osteoporosis and OVCF.
\end{abstract}

Keywords: cobalamin; folate; homocysteine; polymorphism; osteoporosis; compression fracture 


\section{Introduction}

As the number of older people at risk for compromised bone health rapidly increases, identifying new risk factors for osteoporosis has become the center of attention. Researchers have reported many risk factors for osteoporosis and osteoporotic bone fractures, such as age, history of fragility fractures, smoking habits, alcohol intake, steroid use, low bone mineral density (BMD) and hyperhomocysteinemia [1]. Accumulating evidence suggests that high homocysteine level may cause osteoporosis by over production of free radicals and oxidative stress, promotion of osteoclast activity and bone resorption, and inhibition of bone formation. Vitamins are also closely related to bone health. Particularly, vitamins A, D, E and K have been proved to contribute to maintaining bone health [2]. In addition, the role of B-vitamins in bone health has been receiving increasing attention due to both individual action as vitamins and their action on influencing homocysteine concentration [3-7]. Deficiencies in vitamin B6, B9 (folate), and B12 (cobalamin) have been known to cause increased serum levels of homocysteine because these vitamins act as co-factors for various enzymes involved in homocysteine metabolism [1,2]. Cobalamin has been known to increase osteoblast proliferation and cobalamin deficiency may increase osteoclast formation by elevation of homocysteine and mehtylmalnonic acid levels. Folate was also reported to aid maintenance of bone density by helping to preserve optimal nitric oxide synthase activity in the bone cells [7]. Although the effects of vitamin B1 (thiamine) on bone health remains unclear, previous studies show that thiamine may inhibit receptor activator of nuclear factor $\mathrm{kB}$ ligand induced osteoclastogenesis, suggesting a potential link between thiamine deficiency and poor bone health [2].

In addition to these clinical factors, genetic variations within individuals have also been demonstrated to affect the occurrence of osteoporosis and related fractures. Many genetic association studies have confirmed the relationship between reduced BMD, candidate gene polymorphisms, and an increased risk of fracture. Some of the associated polymorphisms reside in vitamin-related genes; among these, polymorphisms within vitamin D-related genes, especially the gene encoding the vitamin $\mathrm{D}$ receptor, have been most widely investigated and are known to be associated with BMD in various populations [8,9]. Despite the role of B vitamins in bone metabolism, there are few studies examining the relationship between polymorphisms of vitamin B-related genes and osteoporosis. Only several homocysteine/folate metabolism-related genes have been linked with osteoporosis to date. For example, a single nucleotide polymorphism (SNPs) in methylenetetrahydrofolate reductase (MTHFR 677 C $>$ T) has been shown to be associated with BMD [10,11]. Recently, it was also reported that SNPs in the 3' untranslated regions (UTRs) of MTHFR (2572 C>A) and thymidylate synthase $(1100 \mathrm{C}>\mathrm{T})$ are associated with the prevalence of osteoporosis and osteoporotic vertebral compression fractures (OVCFs) [12].

Apart from vitamin D, B vitamins are also associated with bone metabolism. Data have suggested that B vitamins, such as folate (vitamin B9) and cobalamin (vitamin B12), affect bone metabolism, bone quality, and fracture risk in humans by contributing to homocysteine/folate metabolism [3-6]. High level of homocysteine may impair collagen cross-link within bone, thereby resulting in decreased bone mineral density and increased susceptibility to fracture $[13,14]$. The folate and cobalamin are important cofactors and should be transported readily to cells. CD320 and TCN2 genes are associated with cobalamin transport. SLC19A1 encodes protein that transport folate. Polymorphisms of those genes may affect the homocysteine metabolism. Despite the role of B vitamins in bone metabolism, there are few studies examining the relationship between vitamin B-related genes and osteoporosis. Only several homocysteine/folate metabolism-related genes have been linked with osteoporosis to date. For example, a single nucleotide polymorphism (SNP) in methylenetetrahydrofolate reductase $($ MTHFR 677C $>$ T) has been shown to be associated with BMD $[10,11]$. Recently, it was also reported that SNPs in the 3' untranslated regions (UTRs) of MTHFR $(2572 \mathrm{C}>\mathrm{A})$ and thymidylate synthase $(1100 \mathrm{C}>\mathrm{T})$ are associated with the prevalence of osteoporosis and osteoporotic vertebral compression fracture (OVCF) [12]. 
B-vitamins should be transported readily to cells to maintain intracellular concentrations. Thiamine can be transported into mammalian cells by thiamine transporter 1, also known as thiamine carrier 1 (TC1) or soluble carrier family 19 member 2 (SLC19A2), which is encoded by the SLC19A2 gene. Cobalamin is absorbed in the distal ileum by binding to gastric intrinsic factor. The absorbed cobalamin then binds to transcobalamin II (TC II, encoded by TCN2 gene) within the enterocyte, and the cobalamin-TC II complex is released into the blood stream. The complex is transported to all tissues where it can be internalized into cells by binding to the TC II receptor (encoded by CD320) [15]. Transport of folate into mammalian cells can occur via folate receptor 1 (RFC1) which in humans is encoded by the SLC19A1 gene. Therefore, we chose four well-known SNPs of B vitamins-related genes, including TCN2 (encodes TC II), CD320 (encodes TC II receptor), SLC19A1 (encodes reduced folate carrier gene (RFC1)), and SLC19A2 (encodes thiamine carrier 1) because polymorphisms of B vitamins-related genes could reduce the availability of B vitamins contributing to the risk of osteoporosis and OVCFs [16,17]. Studies on the relationship between B vitamins and gene polymorphisms are currently insufficient. To the best of our knowledge, there have been no published studies on the association between polymorphisms in vitamin B-related microRNA (miRNA) binding sites (3'-UTR) and osteoporosis and OVCFs. Therefore, in the current study, a database search with MicroSNiPer was used to identify four SNPs in miRNA binding sites within the 3'-UTRs of vitamin B-related genes: CD320 rs9426 C>T, TCN2 rs10418 C>T, SLC19A1 rs1051296 G>T, and SLC19A2 rs16862199 C>T. The minor allele frequency for each of the four SNPs was $>5 \%$ in the Asian population. We then investigated the associations of these four SNPs with osteoporosis and OVCFs in Korean postmenopausal women.

\section{Materials and Methods}

\subsection{Study Design}

We performed a case-control study to examine the relationship between four SNPs in vitamin B-related genes, namely CD320 rs 9426 C > T, TCN2 rs10418 C > T, SLC19A1 rs1051296 G>T, and SLC19A2 rs16862199 C $>\mathrm{T}$, and osteoporosis and OVCF risk. The research was conducted in accordance with the principles described in the Declaration of Helsinki. The institutional Review Board of CHA Bundang Medical Center approved this study (IRB number: BD2015-043), and all participants provided written informed consent.

\subsection{Study Population}

The study group comprised 301 postmenopausal Korean women from the South Korean province of Gyeonggi-do. Postmenopausal women were recruited from the neurosurgery and orthopedic surgery departments at the CHA Bundang Medical Center. Korean postmenopausal women $\geq 50$ years of age were eligible for inclusion in the study. The diagnosis of osteoporosis was based on Dual-energy X-ray absorptiometry (DEXA, Norland Medical Systems, White Plains, NY, USA) of the lumbar spine and hips. Diagnosis of osteoporosis was based on a BMD threshold of 2.5 standard deviations below that of a young adult (T-score, $<-2.5$ or lower) according to the standard World Health Organization criteria. An OVCF was diagnosed when a progressive or newly generated compression fracture was identified after low-energy trauma. An OVCF was defined as a height reduction of the vertebrae $>15 \%$ in any anterior, central, or posterior portion of the vertebrae in plain radiographs [18]. The presence of an OVCF was first determined by a trained neurosurgeon or an orthopedic surgeon and was then confirmed by a radiologist. Computed tomography (CT) or magnetic resonance imaging (MRI) was conducted for subjects with suspicious findings in the plain radiographs or bone scans.

All subjects with osteoporosis met the following criteria: 1) absence of metabolic diseases, such as diffuse idiopathic skeletal hyperostosis, pituitary gland disorders, hyperthyroidism, rheumatoid arthritis, or hyperparathyroidism; 2) no use of drugs that affect bone metabolism or blood clotting, including oral anticoagulants, oral contraceptives, hormone replacement therapy, corticosteroids, calcium, vitamin D, or vitamin B; 3) absence of seronegative spondyloarthropathy; 4) no history of 
stroke or ischemic heart disease; 5) no prior cancer diagnosis; and 6) Korean descent. All subjects were examined using conventional X-radiography, DEXA, and MRI to evaluate the configuration and acuity of the fracture. Whole-body bone scanning was used in cases where MRI was contraindicated.

Control subjects were recruited from individuals who visited the CHA Bundang Medical Center for routine health examinations. Subjects with lumbar spine and hip BMD T-scores $>-1.0$ and no spine or hip fractures were enrolled. The exclusion criteria were identical to those used for the osteoporosis group. Demographic features and comorbidities, such as hypertension, diabetes mellitus, and other cerebro- and cardiovascular diseases, were investigated in all osteoporosis and control subjects. Hypertension was defined as systolic blood pressure (SBP) $>140 \mathrm{mmHg}$ or diastolic blood pressure $(\mathrm{DBP})>90 \mathrm{mmHg}$, including subjects undergoing antihypertensive treatment. Diabetes mellitus (DM) was defined as a fasting plasma glucose level $>126 \mathrm{mg} / \mathrm{dL}$, including subjects who were already diagnosed as diabetic.

\subsection{Blood Sample}

Plasma levels of glucose (reference range, $<100 \mathrm{mg} / \mathrm{dL}$ ), homocysteine (reference range $<12 \mu \mathrm{mol} / \mathrm{L}$ ), folate (reference range, 3.45-13.77 ng/mL), high-density lipoprotein (HDL; reference range, $>40 \mathrm{mg} / \mathrm{dL}$ ), low-density lipoprotein (LDL; reference range, $<130 \mathrm{mg} / \mathrm{dL}$ ), triglycerides (TG; reference range, $<200 \mathrm{mg} / \mathrm{dL}$ ), and vitamin B12 (reference range, 211-911 pg/mL) were measured in fasting blood samples from each subject. Homocysteine was measured by fluorescent polarization immunoassay using an Abbott IMx system (Abbott Laboratories, Abbott Park, IL, USA), folate was measured by competitive immunoassay using ACS:180 (Bayer, Tarrytown, NY, USA), and vitamin B12 was measured using the Bio-Rad Quantaphase II radioassay (Hercules, CA, USA). All assays were conducted according to manufacturer's instructions. HDL, LDL, and TG concentrations were assessed using standard hospital protocols.

\subsection{Genetic Analyses}

We collected $5 \mathrm{~mL}$ of peripheral blood by tube coated with anticoagulant, separated the buffy coat with leukocytes through centrifugation, and extracted genomic DNA using the G-DEXIIb kit (iNtRon Inc., Seongnam, South Korea). The experiment procedure was as follows. We mixed thoroughly 1.5 $\mathrm{mL}$ peripheral blood and RBC lysis solution and incubated for $5 \mathrm{~min}$ at room temperature. During incubation we turned it over again at least once. After $5 \mathrm{~min}$, centrifugation was performed at 10,000× $\mathrm{g}$ for $1 \mathrm{~min}$. Subsequently, the supernatant was removed except for the white blood cell pellet. After vortexing to resuspend the cell pellet in the tube, cell lysis solution was added to the resuspended cells and pipetted up and down to lyse the cells at room temperature. When the cells were sufficiently lysed, $100 \mu \mathrm{L}$ of PPT buffer was added to the cell lysate, vortexed vigorously at high speed for 20 sec, and centrifugation was performed at $13,000 \times g$ for $5 \mathrm{~min}$. The supernatant containing DNA was transferred to a new $1.5 \mathrm{~mL}$ tube, $300 \mu \mathrm{L} 100 \%$ isopropanol (2-propanol) was added, and the sample was mixed by gently inverting several times. Thereafter, the supernatant was removed from the clean absorbent paper by centrifugation at $13,000 \times \mathrm{g}$ for $1 \mathrm{~min}$. In the next step, $1 \mathrm{~mL} 70 \%$ ethanol was added, the tube was inverted several times to wash the DNA pellet, and centrifuged for $1 \mathrm{~min}$ at $13,000 \times \mathrm{g}$. We removed the supernatant, inverted, drained the tube from a clean absorbent paper and air dried for $10 \mathrm{~min}$. After drying sufficiently, $150 \mu \mathrm{L}$ of DNA rehydration buffer was added. After rehydration of the DNA by incubation at $65^{\circ} \mathrm{C}$ for $60 \mathrm{~min}$, DNA purity was confirmed by measurement of the O.D 260: 280 ratio, and stored at $-20^{\circ} \mathrm{C}$ for long-term storage. We genotyped the $3^{\prime}$-UTR polymorphisms of CD320 rs9426 C> T, TCN2 rs10418 C>T, SLC19A1 rs1051296 G>T, and SLC19A2 rs16862199 C>T SNPs by polymerase chain reaction-restriction fragment length polymorphism (PCR-RFLP) (Figure 1). The PCRs were performed using the following primers, which were designed by PrimerQuest (Integrated DNA Technologies, Coralville, IA, USA): CD320 rs9426 C>T, forward primer 5'-TGT CTT AAG CAC AGG GCC GTT CTA-3' and reverse primer 5'-GGT CCC TGG ACA CTC CCC ATG-3'; TCN2 rs10418 C>T, forward primer 5'-ACT CTG TTA GAG TGG CAG ATC-3' and reverse primer 5'-GCT TTA ATT TTG 
TCA GAG GCA GG-3'; SLC19A1 rs1051296 G>T, forward primer 5'-GCT TCT CTG TCT CTG TGG AAA-3' and reverse primer 5'-AAG CCT GGC ACA TAC CAA-3'; and SLC19A2 rs16862199 C>T, forward primer 5'-GCA GGA ATC ACA TCT ATC CTA GTT CC-3' and reverse primer 5'-GCT TAA GGT ACG CTT GCT TGT C-3'. The underlined bases indicate mismatches with the complementary sequence. For RFLP analysis of the SNPs, the PCR products for CD320, TCN2, SLC19A1, and SLC19A2 were digested with the restriction enzymes StyI, BglII, BanI, and Hpy188I, respectively. To confirm the four SNPs and validate the RFLP results, $10 \%-20 \%$ of the samples were randomly selected, used for a second round of PCR, and analyzed by DNA sequencing using an automatic ABI3730xL DNA analyzer (Applied Biosystems, Forster City, CA, USA). The concordance of the quality control sample was $100 \%$.
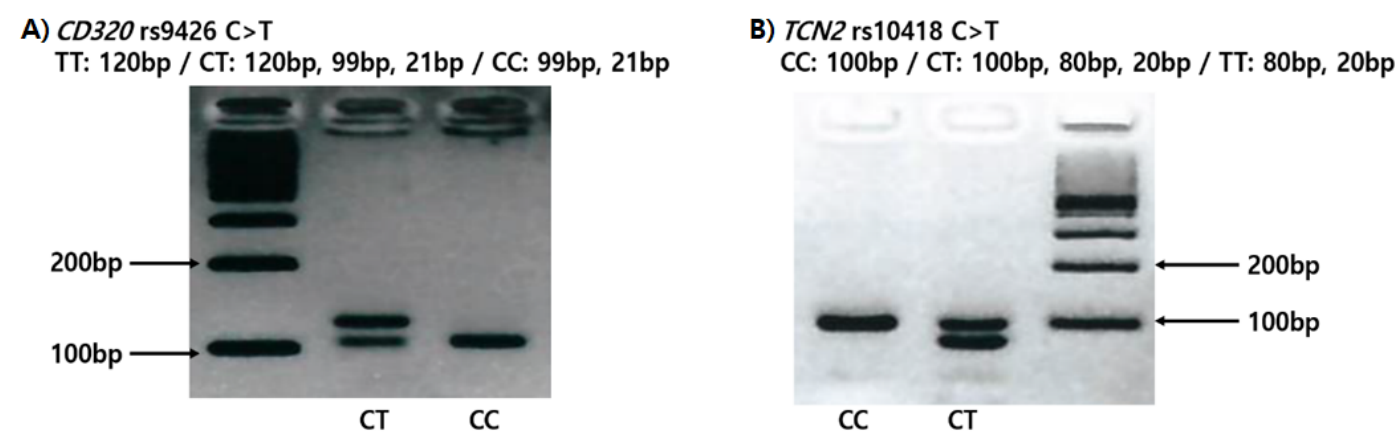

D) SLC19A2 rs16862199 A>G

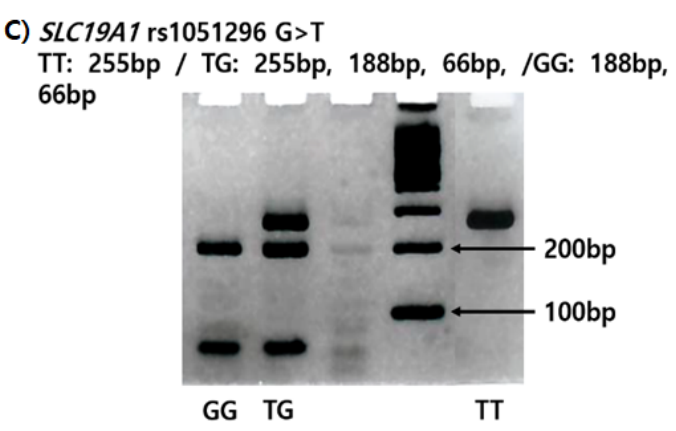

TT: 309bp / CT: 309bp, 200bp, 109bp / CC: 200bp, 109bp

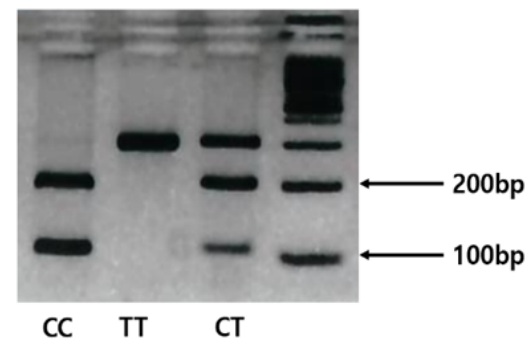

Figure 1. Restriction fragment length polymorphism (RFLP) variations according to genotypes. (A) CD320 rs9426 C>T (B) TCN2 rs10418 C>T (C) SLC19A1 rs1051296 G>T (D) SLC19A2 rs16862199 $C>T$.

\subsection{Statistical Analyses}

Differences between groups were assessed using the chi-squared test and Student's t-test for categorical variables and continuous variables, respectively. Multivariate logistic regression and Fisher's exact test were used to compare the genotype and allele combination frequencies, respectively, between cases (osteoporosis group, including non-OVCF and OVCF subjects) and controls. Allele frequencies were evaluated for deviation from Hardy-Weinberg equilibrium using a threshold of $p=0.05$. To estimate the relative risk for osteoporosis with respect to subject genotype in the non-OVCF and OVCF groups, the odds ratio (OR) and 95\% confidence interval (CI) were calculated. Analysis of variance (ANOVA) was used to analyze the association of the genotypes with BMD, body mass index (BMI), DBP, SBP, and levels of glucose, homocysteine, folate, HDL, LDL, TG, and vitamin B12. A p-value $\leq 0.05$ was considered to indicate statistical significance. ORs were adjusted (AOR) for possible confounders, such as age, sex, DM, hypertension, and serum folate and vitamin B12 levels. Statistical analyses were performed using GraphPad Prism 4.0 software (GraphPad Software, Inc., San Diego, CA, USA), MedCalc v.18.11.3 software (MedCalc Software, Mariakerke, Belgium), and HAPSTAT 3.0 (University of North Carolina, Chapel Hill, NC). We constructed all possible allele combinations for the four SNPs and analyzed gene-gene interactions using the multifactor dimensionality reduction (MDR) method (MDR software package v.2.0, www.epistasis.org) [19]. 


\section{Results}

\subsection{Patient Characteristics}

The mean ages in the control group $(n=158)$ and osteoporosis group $(n=143)$ were $69.36 \pm 6.26$ years and $69.38 \pm 7.25$ years, respectively. Of the 143 subjects with osteoporosis (osteoporosis group), 74 patients were diagnosed with OVCF (OCVF group). When comparing the control group with the osteoporosis group, we found that patients with osteoporosis were significantly more likely to have higher blood glucose levels, lower BMI, and decreased LDL and vitamin B12 levels. Patients in the OVCF group had significantly higher blood glucose levels, lower folate levels, and lower BMIs than subjects in the control group [9] (Table 1).

\subsection{Genotype Frequencies of CD320, TCN2, SLC19A1, and SLC19A2 SNPS}

The genotype and allele frequencies of the CD320 rs9426 C>T, TCN2 rs10418 C>T, SLC19A1 rs1051296 G>T, and SLC19A2 rs16862199 C>T SNPs were compared between control subjects and osteoporosis patients with or without OVCF. There were no statistically significant differences in genotype or allele frequencies between the control and osteoporosis groups for any of the four SNPs (Figure 2; Table 2).

A)

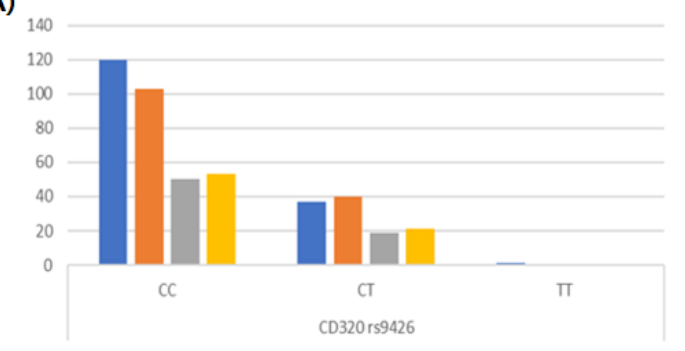

C)

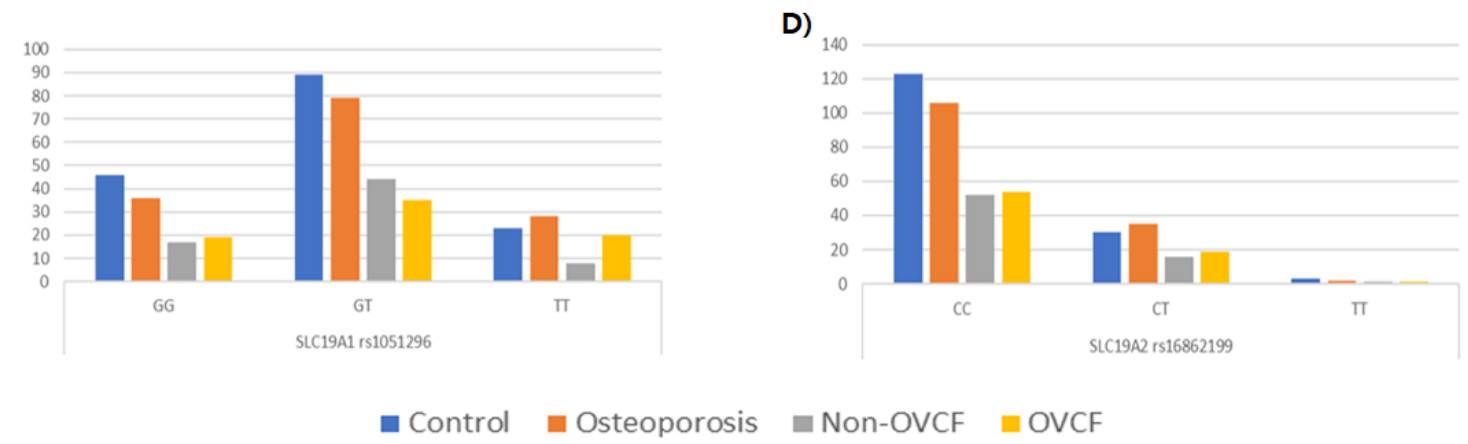

B)

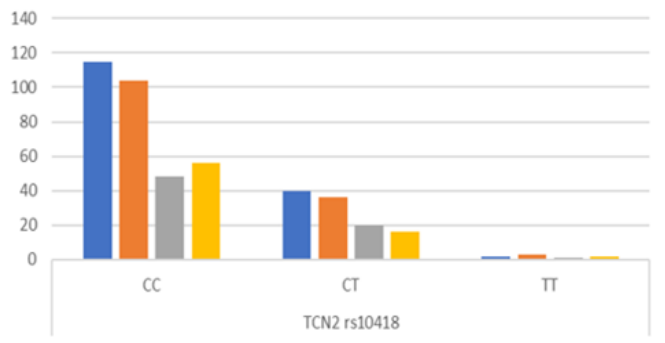

D)

Figure 2. Genotype frequencies of single nucleotide polymorphisms. (A) CD320 rs9426 C>T (B) TCN2 rs10418 C>T (C) SLC19A1 rs1051296 G>T (D) SLC19A2 rs16862199 C>T.

\subsection{Allele Combination Analysis Using the MDR Method}

We then used the MDR method to compare allele combination frequencies for the four SNPs between the control and osteoporosis groups (Table 3). The allele combinations listed below are presented according to the following gene order: CD320, TCN2, SLC19A1, and SLC19A2. The allele combination analysis revealed significant differences between the groups. Specifically, two allele combinations differed significantly between the control and osteoporosis (non-OVCF and OVCF) groups: C-T-T-C (OR 3.244; 95\% CI 1.478-7.120, $p<0.05$ ) and T-C-G-C (OR 2.287; 95\% CI 1.094-4.782, $p<0.05)$. Five allele combinations demonstrated significant differences between the control and OVCF groups: C-C-G-T (OR 1.280; 95\% CI 1.280-7.386, p < 0.05), C-C-T-C (OR 1.028; 95\% CI 1.028-2.788, 
$p<0.05$ ), C-C-T-T (OR 1.522; CI 1.522-15.900, $p<0.05$ ), C-T-T-C (OR 1.482; 95\% CI 1.482-9.187, $p<0.05$ ), and T-C-G-C (OR 1.556; 95\% CI 1.556-8.089, $p<0.05)$. Three allele combinations showed significant differences between the control and non-OVCF groups: C-T-G-C (OR 0.075; CI 0.075-0.887, $p<0.05$ ), C-T-G-T (OR 1.098; CI 1.098-393.000, $p<0.05$ ), and C-T-T-C (OR 1.133; 95\% CI 1.133-6.844, $p<0.05$ ). Among these combinations, combination C-T-G-T in the osteoporosis group demonstrated the highest OR (OR, 14.850; 95\% CI, 0.810-272.100, $p<0.05)$.

\subsection{Stratified and Interactions Analyses between CD320, TCN2, SLC19A1, and SLC19A2 SNPS and Clinical Parameters}

To determine whether the four SNPs were associated with osteoporosis and OVCF prevalence in specific subsets of patients, we conducted a stratified analysis of the data according to age, hypertension, DM, and serum levels of folate, vitamin B12, and homocysteine. To enable interaction analyses for serum levels, we established cut-off values for folate, vitamin B12, and homocysteine, using cut-offs at the bottom $15 \%$ for folate $(4.59 \mathrm{nmol} / \mathrm{L})$ and B12 $(395 \mathrm{pg} / \mathrm{mL})$, and a cut-off at the top $15 \%$ for homocysteine $(12.68 \mu \mathrm{mol} / \mathrm{L})$.

The incidence of osteoporosis was significantly higher for genotype CD320 rs9426 CT+TT than genotype CC both in patients $\geq 69$ years of age (AOR 2.399, CI 1.101-5.226) and in patients with high homocysteine concentrations (homocysteine $>12.68 \mu \mathrm{mol} / \mathrm{L})$ (AOR 5.019, CI 1.533-16.430, $p<0.05$; Figure 3A). The incidence of osteoporosis was also significantly higher for genotype TCN2 CT+TT than genotype CC in subsets of patients without hypertension, with diabetes, with low folate levels, or with low homocysteine concentrations (Table 4). To evaluate the effect of the dominant genotype in the stratified conditions of each parameter, each SNP was also analyzed using a dominant model. There were no significant differences between dominant and recessive SNPs (Supplementary Table S1).

Next, the incidence of OVCF was analyzed with respect to each SNP. The results showed that OVCF incidence was increased for genotype CD320 rs9426 CT+TT compared to genotype CC both in patients with low folate levels (AOR 7.307, CI 1.975-27.033) and in patients with high homocysteine concentrations (homocysteine $>12.68 \mu \mathrm{mol} / \mathrm{L}$ ) (AOR 5.760, CI 1.480-22.417, $p<0.05$; Figure 3B). The genotype SLC19A1 rs1051296 GT+TT was also associated with a higher incidence of OVCF than genotype GG in patients with low folate levels (AOR 3.589, CI 1.440-8.950; Table 5). In the stratified conditions of each parameter, the dominant model did not demonstrate significant differences, although genotype CD320 rs9426 CT+TT exhibited an increased frequency of OVCF in patients with low folate levels (AOR 2.040, CI 0.500-8.322) or high homocysteine concentrations (AOR 3.500, CI 0.795-15.400; Supplementary Table S2). 


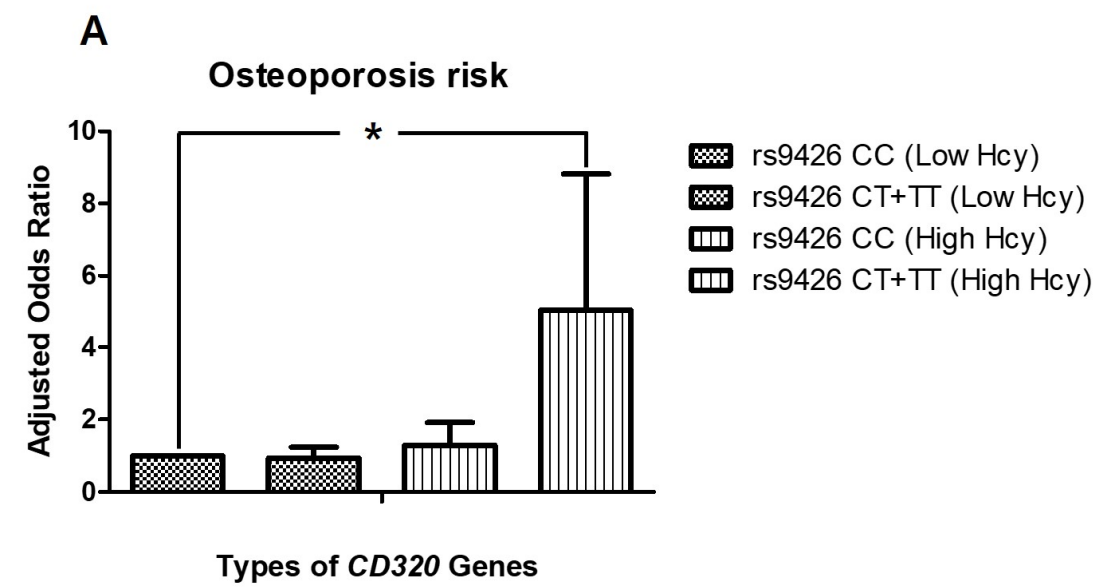

B

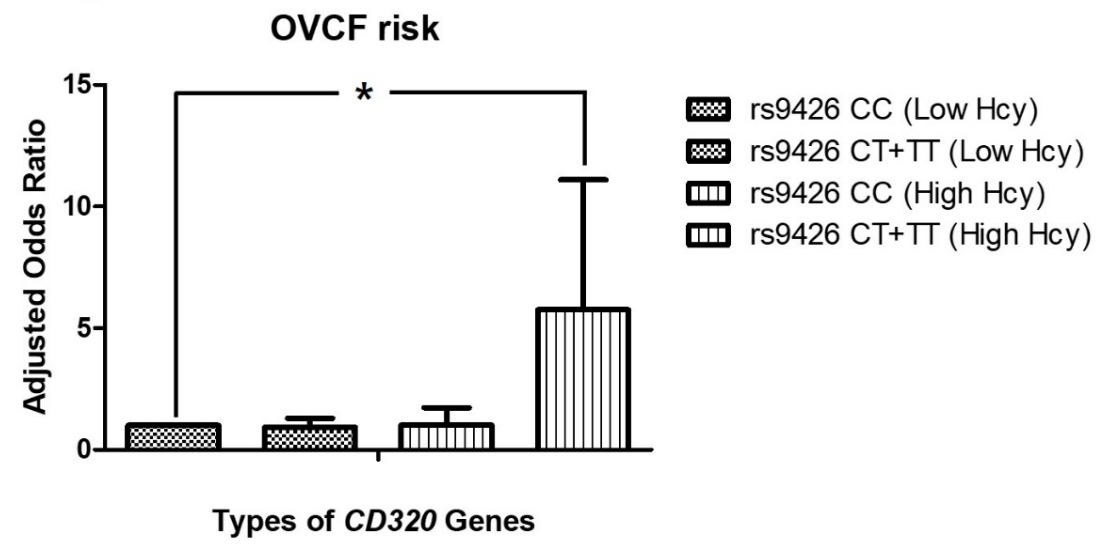

Figure 3. (A) Osteoporosis risk stratified by interaction between $C D 320$ rs $9426 \mathrm{C}>\mathrm{T}$ and homocysteine levels (B) OVCF risk stratified by interaction between CD320 rs9426 C>T and homocysteine levels. Hcy, homocysteine; OVCF, osteoporotic vertebral compression fracture; ${ }^{*} p<0.05$. 
Table 1. Baseline characteristics of control and osteoporosis groups.

\begin{tabular}{|c|c|c|c|c|c|c|c|}
\hline Characteristic & Control $(n=158)$ & Osteoporosis $(n=143)$ & $p^{*}$ & Non-OVCF $(n=69)$ & $p^{* *}$ & OVCF $(n=74)$ & $p^{* * *}$ \\
\hline Age (years, mean $\pm \mathrm{SD}$ ) & $69.36 \pm 6.26$ & $69.38 \pm 7.25$ & 0.983 & $70.83 \pm 6.53$ & 0.207 & $70.23 \pm 9.44$ & 0.282 \\
\hline Hypertension $(n)$ & $79(50.0 \%)$ & $52(36.4 \%)$ & 0.134 & $20(29.0 \%)$ & $<0.0001$ & $32(43.2 \%)$ & 0.0007 \\
\hline $\mathrm{SBP}(\mathrm{mmHg}$, mean $\pm \mathrm{SD})$ & $135.92 \pm 18.65$ & $127.32 \pm 14.44$ & $<0.0001$ & $126.54 \pm 13.76$ & 0.0002 & $128.13 \pm 15.16$ & 0.003 \\
\hline $\mathrm{DBP}(\mathrm{mmHg}$, mean $\pm \mathrm{SD})$ & $80.73 \pm 11.52$ & $75.48 \pm 10.33$ & 0.0001 & $74.42 \pm 10.24$ & 0.0001 & $76.57 \pm 10.38$ & 0.012 \\
\hline Diabetes mellitus (n) & $22(13.9 \%)$ & $26(18.2 \%)$ & 0.392 & $17(24.6 \%)$ & 0.645 & $9(12.2 \%)$ & 0.05 \\
\hline FBS $(\mathrm{mg} / \mathrm{dL}$, mean $\pm \mathrm{SD})$ & $111.78 \pm 28.12$ & $123.56 \pm 43.20$ & 0.006 & $114.70 \pm 26.41$ & 0.466 & $132.56 \pm 54.01$ & 0.0002 \\
\hline Homocysteine $(\mu \mathrm{mol} / \mathrm{L}$, mean $\pm \mathrm{SD})$ & $9.74 \pm 3.04$ & $9.83 \pm 4.09$ & 0.83 & $9.54 \pm 4.35$ & 0.69 & $10.11 \pm 3.84$ & 0.441 \\
\hline Folate $(\mathrm{ng} / \mathrm{mL}$, mean $\pm \mathrm{SD})$ & $9.51 \pm 6.48$ & $8.28 \pm 4.87$ & 0.074 & $10.27 \pm 4.95$ & 0.408 & $6.57 \pm 4.11$ & 0.0005 \\
\hline $\mathrm{BMI}\left(\mathrm{kg} / \mathrm{m}^{2}\right.$, mean $\left.\pm \mathrm{SD}\right)$ & $24.52 \pm 3.11$ & $23.48 \pm 3.81$ & 0.045 & $23.88 \pm 2.77$ & 0.173 & $21.37 \pm 6.98$ & 0.005 \\
\hline $\mathrm{HDL}(\mathrm{mg} / \mathrm{dL}$, mean $\pm \mathrm{SD})$ & $47.67 \pm 12.13$ & $44.78 \pm 14.24$ & 0.223 & $44.42 \pm 12.27$ & 0.18 & $45.16 \pm 16.19$ & 0.385 \\
\hline $\mathrm{LDL}(\mathrm{mg} / \mathrm{dL}$, mean $\pm \mathrm{SD})$ & $130.30 \pm 44.64$ & $107.31 \pm 39.55$ & 0.002 & $95.18 \pm 32.38$ & $<0.0001$ & $120.64 \pm 42.64$ & 0.281 \\
\hline $\mathrm{TG}(\mathrm{mg} / \mathrm{dL}$, mean $\pm \mathrm{SD})$ & $152.85 \pm 87.54$ & $146.81 \pm 81.90$ & 0.567 & $133.89 \pm 87.61$ & 0.169 & $159.05 \pm 74.81$ & 0.633 \\
\hline Vitamin B12 $(\mathrm{pg} / \mathrm{mL}$, mean $\pm \mathrm{SD})$ & $824.92 \pm 919.42$ & $593.13 \pm 353.52$ & 0.033 & $552.61 \pm 292.27$ & 0.023 & $750.13 \pm 510.97$ & 0.75 \\
\hline $\mathrm{BMD}\left(\mathrm{g} / \mathrm{cm}^{2}\right.$, mean $\left.\pm \mathrm{SD}\right)$ & - & $-3.04 \pm 0.94$ & - & $-3.13 \pm 0.62$ & - & $-2.93 \pm 1.21$ & - \\
\hline
\end{tabular}

SD, standard deviation; OVCF, osteoporotic vertebral compression fracture; SBP, systolic blood pressure; DBP, diastolic blood pressure; FBS, fasting blood sugar; BMI, body mass index; HDL, high density lipoprotein; LDL, low density lipoprotein; TG, triglyceride; BMD, bone mineral density. $p^{*}$ —Osteoporosis versus Controls, $p$ ** —Non OVCF vs Controls, and $p$ ***-OVCF vs Controls. 
Table 2. Genotype frequencies for the 3'-UTR polymorphisms of CD320, TCN2, SLC19A1 and SLC19A2 genes in control and OVCF groups.

\begin{tabular}{|c|c|c|c|c|c|c|c|c|c|c|}
\hline Genotype $^{+}$ & $\begin{array}{l}\text { Control (n = } \\
158), \mathrm{n}(\%)\end{array}$ & $\begin{array}{l}\text { Osteoporosis } \\
(\mathrm{n}=143), \mathrm{n}(\%)\end{array}$ & $\operatorname{AOR}^{a}(95 \% \mathrm{CI})$ & $p^{*}$ & $\begin{array}{c}\text { Non-OVCF } \\
(n=69)\end{array}$ & AOR $(95 \% \mathrm{CI})$ & $p^{* *}$ & $\begin{array}{l}\text { OVCF } \\
(\mathrm{n}=74)\end{array}$ & AOR $(95 \% \mathrm{CI})$ & $p^{* * *}$ \\
\hline \multicolumn{11}{|l|}{ CD320C $>\mathrm{T}$ (rs9426) } \\
\hline $\mathrm{CC}$ & $120(75.9)$ & $103(72.0)$ & 1.000 (reference) & & $50(72.5)$ & 1.000 (reference) & & $53(71.6)$ & 1.000 (reference) & \\
\hline $\mathrm{CT}$ & $37(23.4)$ & $40(28.0)$ & $1.256(0.738-2.138)$ & 0.401 & $19(27.5)$ & $1.246(0.638-2.434)$ & 0.520 & $21(28.4)$ & $1.408(0.731-2.712)$ & 0.307 \\
\hline TT & $1(0.6)$ & $0(0.0)$ & N/A & 0.998 & $0(0.0)$ & N/A & 0.998 & $0(0.0)$ & N/A & 0.998 \\
\hline Dominant (CC vs $\mathrm{CT}+\mathrm{TT})$ & & & $1.222(0.720-2.074)$ & 0.459 & & $1.210(0.621-2.359)$ & 0.576 & & $1.369(0.712-2.630)$ & 0.347 \\
\hline Recessive (CC+CT vs TT) & & & N/A & 0.998 & & N/A & 0.998 & & N/A & 0.998 \\
\hline HWE- $P$ & 0.264 & 0.052 & & & & & & & & \\
\hline \multicolumn{11}{|l|}{ TCN2C > T (rs10418) } \\
\hline CC & $115(73.2)$ & $104(72.7)$ & 1.000 (reference) & & $48(69.6)$ & 1.000 (reference) & & $56(75.7)$ & 1.000 (reference) & \\
\hline СТ & $40(25.5)$ & $36(25.2)$ & $1.015(0.593-1.736)$ & 0.957 & $20(29.0)$ & $1.342(0.690-2.610)$ & 0.387 & $16(21.6)$ & $0.750(0.372-1.513)$ & 0.422 \\
\hline TT & $2(1.3)$ & $3(2.1)$ & $0.853(0.182-3.993)$ & 0.840 & $1(1.4)$ & $0.665(0.067-6.645)$ & 0.729 & $2(2.7)$ & $1.215(0.211-7.000)$ & 0.828 \\
\hline Dominant (CC vs $\mathrm{CT}+\mathrm{TT})$ & & & 1.007 (0.599-1.695) & 0.978 & & $1.279(0.668-2.447)$ & 0.458 & & $0.800(0.410-1.561)$ & 0.514 \\
\hline Recessive (CC+CT vs TT) & & & $0.884(0.192-4.077)$ & 0.874 & & $0.611(0.062-5.998)$ & 0.673 & & $1.372(0.240-7.841)$ & 0.722 \\
\hline HWE- $P$ & 0.473 & 0.955 & & & & & & & & \\
\hline \multicolumn{11}{|l|}{ SLC19A1G >T (rs1051296) } \\
\hline GG & $46(29.1)$ & $36(25.2)$ & 1.000 (reference) & & $17(24.6)$ & 1.000 (reference) & & $19(25.7)$ & 1.000 (reference) & \\
\hline GT & $89(56.3)$ & $79(55.2)$ & 1.059 (0.611-1.835) & 0.839 & $44(63.8)$ & $1.241(0.623-2.474)$ & 0.539 & $35(47.3)$ & $0.868(0.436-1.727)$ & 0.686 \\
\hline TT & $23(14.6)$ & $28(19.6)$ & $1.388(0.653-2.949)$ & 0.394 & $8(11.6)$ & $0.853(0.303-2.401)$ & 0.763 & $20(27.0)$ & $1.659(0.686-4.009)$ & 0.261 \\
\hline Dominant (GG vs GT+TT) & & & $1.098(0.649-1.858)$ & 0.727 & & $1.138(0.582-2.227)$ & 0.705 & & $0.990(0.516-1.898)$ & 0.975 \\
\hline Recessive (GG+GT vs TT) & & & $1.253(0.658-2.387)$ & 0.493 & & $0.713(0.290-1.751)$ & 0.460 & & $1.670(0.796-3.505)$ & 0.175 \\
\hline HWE- $P$ & 0.058 & 0.195 & & & & & & & & \\
\hline \multicolumn{11}{|l|}{$S L C 19 A 2 C>T(\operatorname{rs} 16862199)$} \\
\hline $\mathrm{CC}$ & $123(78.8)$ & $106(74.1)$ & 1.000 (reference) & & $52(75.4)$ & 1.000 (reference) & & $54(73.0)$ & 1.000 (reference) & \\
\hline $\mathrm{CT}$ & $30(19.2)$ & $35(24.5)$ & $1.395(0.794-2.451)$ & 0.248 & $16(23.2)$ & $1.124(0.545-2.317)$ & 0.752 & $19(25.7)$ & $1.678(0.842-3.344)$ & 0.142 \\
\hline TT & $3(1.9)$ & $2(1.4)$ & $0.823(0.133-5.093)$ & 0.834 & $1(1.4)$ & $0.930(0.090-9.660)$ & 0.952 & $1(1.4)$ & $0.831(0.082-8.417)$ & 0.875 \\
\hline Dominant (CC vs $\mathrm{CT}+\mathrm{TT})$ & & & $1.345(0.778-2.326)$ & 0.288 & & $1.118(0.554-2.255)$ & 0.756 & & $1.607(0.822-3.142)$ & 0.166 \\
\hline Recessive (CC+CT vs TT) & & & $0.758(0.124-4.646)$ & 0.764 & & $0.915(0.089-9.423)$ & 0.941 & & $0.782(0.079-7.737)$ & 0.833 \\
\hline HWE- $P$ & 0.602 & 0.640 & & & & & & & & \\
\hline
\end{tabular}

† Odds ratio adjusted by age, gender, hypertension, diabetes mellitus, BMI, glucose and folate $p^{*}$-Osteoporosis versus Controls, $p^{* *}-\mathrm{Non}$ OVCF vs Controls, and $p^{* * *}-\mathrm{OVCF}$

Controls. AOR, adjusted odds ratio; CI, confidence interval; $\mathrm{OVCF}$, osteoporotic vertebral compression fracture, HWE- $P$, Hardy-Weinberg equilibrium p-value; $\mathrm{N} / \mathrm{A}$, not applicable. 
Table 3. Allele combination analysis for four vitamin B-related genes (CD320, TCN2, SLC19A1, and SLC19A2) using the multifactor dimensionality reduction method to compare genotype frequencies between OVCF and control groups.

\begin{tabular}{|c|c|c|c|c|c|c|c|c|c|c|}
\hline Allele Combination & $\begin{array}{c}\text { Control }^{\dagger} \\
(2 n=316)\end{array}$ & $\begin{array}{l}\text { Osteoporosis }^{\dagger} \\
(2 \mathrm{n}=286)\end{array}$ & OR $(95 \% \mathrm{CI})$ & $p^{*}$ & $\begin{array}{c}\text { Non-OVCF } \\
(2 \mathrm{n}=148)\end{array}$ & OR $(95 \% \mathrm{CI})$ & $p^{* *}$ & $\begin{array}{c}\text { OVCF }^{\dagger} \\
(2 n=138)\end{array}$ & OR $(95 \% \mathrm{CI})$ & $p^{* * *}$ \\
\hline \multicolumn{11}{|c|}{$C D 320$ rs9246C $>\mathrm{T} / \mathrm{TCN} 2 \mathrm{rs10418C}>\mathrm{T} / \mathrm{RFC}$ rs1051296G $>\mathrm{T} / \mathrm{SLC19A2}$ rs16862199C $>\mathrm{T}$} \\
\hline C-C-G-C & 0.390 & 0.317 & 1.000 (reference) & & 0.386 & 1.000 (reference) & & 0.269 & 1.000 (reference) & \\
\hline C-C-G-T & 0.039 & 0.062 & $2.027(0.930-4.420)$ & 0.080 & 0.039 & $0.324(0.324-2.882)$ & 1.000 & 0.079 & $1.280(1.280-7.386)$ & 0.014 \\
\hline C-C-T-C & 0.282 & 0.308 & $1.336(0.896-1.995)$ & 0.185 & 0.266 & $0.585(0.585-1.592)$ & 0.899 & 0.329 & $1.028(1.028-2.788)$ & 0.043 \\
\hline C-C-T-T & 0.016 & 0.038 & $2.974(0.998-8.858)$ & 0.065 & 0.024 & $0.321(0.321-6.041)$ & 0.701 & 0.055 & $1.522(1.522-15.900)$ & 0.008 \\
\hline C-T-G-C & 0.087 & 0.032 & $0.451(0.202-1.005)$ & 0.065 & 0.023 & $0.075(0.075-0.887)$ & 0.025 & 0.042 & $0.263(0.263-1.774)$ & 0.506 \\
\hline C-T-G-T & 0.000 & 0.017 & $14.850(0.810-272.100)$ & 0.015 & 0.028 & $1.098(1.098-393.000)$ & 0.009 & 0.001 & N/A & \\
\hline C-T-T-C & 0.033 & 0.083 & $3.244(1.478-7.120)$ & 0.003 & 0.088 & $1.133(1.133-6.844)$ & 0.030 & 0.083 & $1.482(1.482-9.187)$ & 0.005 \\
\hline C-T-T-T & 0.031 & 0.002 & $0.135(0.017-1.075)$ & 0.030 & 0.009 & $0.029(0.029-1.860)$ & 0.182 & 0.000 & $0.008(0.008-2.535)$ & 0.119 \\
\hline T-C-G-C & 0.042 & 0.078 & $2.287(1.094-4.782)$ & 0.029 & 0.048 & $0.472(0.472-3.309)$ & 0.619 & 0.102 & $1.556(1.556-8.089)$ & 0.003 \\
\hline T-C-G-T & 0.006 & 0.013 & $2.703(0.484-15.090)$ & 0.407 & 0.030 & $0.824(0.824-26.130)$ & 0.078 & 0.000 & $0.029(0.029-12.980)$ & 1.000 \\
\hline T-C-T-C & 0.040 & 0.036 & $1.040(0.437-2.477)$ & 1.000 & 0.048 & $0.472(0.472-3.309)$ & 0.619 & 0.030 & $0.292(0.292-3.068)$ & 1.000 \\
\hline T-C-T-T & 0.026 & 0.000 & $0.079(0.005-1.394)$ & 0.022 & 0.000 & $0.008(0.008-2.397)$ & 0.107 & 0.000 & $0.010(0.010-3.179)$ & 0.200 \\
\hline T-T-G-C & 0.006 & 0.009 & $2.027(0.332-12.390)$ & 0.654 & 0.011 & $0.318(0.318-16.920)$ & 0.587 & 0.000 & $0.029(0.029-12.980)$ & 1.000 \\
\hline T-T-T-C & 0.002 & 0.000 & $0.450(0.018-11.180)$ & 1.000 & 0.001 & N/A & & 0.003 & $0.041(0.041-25.470)$ & 1.000 \\
\hline T-T-T-T & 0.000 & 0.004 & $4.049(0.163-100.600)$ & 0.428 & 0.000 & $0.031(0.031-19.210)$ & 1.000 & 0.007 & $0.365(0.365-229.200)$ & 0.250 \\
\hline
\end{tabular}

† The allele combination models were indicated by frequency. $p$-value calculated by Fisher's exact test. $p^{*}$-Osteoporosis versus Controls, $p^{* *}-\mathrm{Non}$ OVCF vs Controls, and $p^{* * *}-\mathrm{OVCF}$

vs Controls. OR, odds ratio; CI, confidence interval; $\mathrm{OVCF}$, osteoporotic vertebral compression fracture. 
Table 4. Stratified analysis of osteoporosis incidence by interactions with age, hypertension, diabetes mellitus, and levels of vitamin B12, folate, and homocysteine.

\begin{tabular}{|c|c|c|c|c|c|c|c|c|}
\hline \multirow{2}{*}{ Variables $^{\dagger}$} & \multicolumn{2}{|c|}{ CD320 rs9426 CC vs. CT+TT } & \multicolumn{2}{|c|}{ TCN2 rs10418 CC vs. CT+TT } & \multicolumn{2}{|c|}{ SLC19A1 rs1051296 GG vs. GT+TT } & \multicolumn{2}{|c|}{ SLC19A2 rs16862199 CC vs. CT+TT } \\
\hline & AOR $(95 \% \mathrm{CI})$ & AOR $(95 \% \mathrm{CI})$ & AOR $(95 \% \mathrm{CI})$ & AOR $(95 \% \mathrm{CI})$ & AOR $(95 \% \mathrm{CI})$ & AOR $(95 \% \mathrm{CI})$ & AOR $(95 \% \mathrm{CI})$ & AOR $(95 \% \mathrm{CI})$ \\
\hline \multicolumn{9}{|l|}{ Age (years) } \\
\hline$<69$ & 1.000 (reference) & $0.698(0.316-1.540)$ & 1.000 (reference) & $0.944(0.486-1.835)$ & 1.000 (reference) & $2.731(1.170-6.375)$ & 1.000 (reference) & $1.354(0.577-3.176)$ \\
\hline$\geq 69$ & $1.050(0.607-$ & 2.399 & $0.936(0.479$ & $1.848(0.9$ & 4.105 & 2.740 & 1.361 & $1.943(0.91$ \\
\hline \multicolumn{9}{|l|}{ Hypertension } \\
\hline & 00 & 1.685 & 1.000 (reference) & 2) & 1.00 & 2) & 1.00 & 2.488 \\
\hline Yes & $0.766(0.441-1$ & $0.631(0.272-$ & 1.000 & 0.775 & 0.783 & $0.703(0.332-$ & $0.839(0.486-1.450)$ & $0.561(0.245-1.288)$ \\
\hline \multicolumn{9}{|l|}{$\begin{array}{l}\text { Diabetes } \\
\text { mellitus }\end{array}$} \\
\hline No & $1.000(\mathrm{re}$ & 1.330 & 000 & 1.191 & 1.000 & 1.293 & 1.00 & $1.655(0.8$ \\
\hline Yes & $1.726(0.828-3.598)$ & $1.721(0.553-5.362)$ & $0.800(0.334-1.914)$ & $3.413(1.245-9.358)$ & $1.810(0.600-5.458)$ & $1.595(0.681-3.738)$ & $2.111(0.978-4.555)$ & $1.193(0.422-3.370)$ \\
\hline \multicolumn{9}{|l|}{ Vitamin $B 12^{\mathrm{a}}$} \\
\hline$>395 \mathrm{pg} / \mathrm{mL}$ & 1.000 & 1.273 & $1.000(\mathrm{re}$ & 1.200 & 1.00 & 1.256 & 1.00 & 1.200 \\
\hline $\begin{array}{c}\leq 395 \mathrm{pg} / \mathrm{mL} \\
\text { Folate }^{\mathrm{a}}\end{array}$ & $2.765(1.198-6.382)$ & $3.437(0.646-18.278)$ & $2.164(0.936-5.004)$ & $4.454(0.893-22.208)$ & $3.099(0.713-13.470)$ & $2.442(0.939-6.353)$ & $2.164(0.936-5.004)$ & $4.454(0.893-22.208)$ \\
\hline$>4.59 \mathrm{nmol} / \mathrm{L}$ & 1.000( & 1.325 & & & & & 1.00 & 1.708 (0. \\
\hline & $1.961(0.907-4.238)$ & $2.157(0.576-8.082)$ & $1.392(0.517-3.752)$ & $2.475(1.014-6.041)$ & $1.000(0.248-4.033)$ & $2.019(0.878-4.646)$ & $2.032(0.906-4.561)$ & $1.837(0.582-5.796)$ \\
\hline \multicolumn{9}{|l|}{ Homocysteine $\mathrm{a}^{\mathrm{a}}$} \\
\hline$<12.68 \mu \mathrm{mol} / \mathrm{L}$ & $1.000(\mathrm{r}$ & 0.936 & 1.000 & 1.646 & 1.00 & 1.484 & 1.000 & $1.591(0.857-2.954)$ \\
\hline$\geq 12.68 \mu \mathrm{mol} / \mathrm{L}$ & $1.293(0.547-3.055)$ & 5.019 (1.533-16.430) & 3.411 (1.213-9.595) & $1.837(0.783-4.312)$ & $5.385(1.355-21.400)$ & $1.831(0.783-4.280)$ & $2.646(1.141-6.132)$ & $1.569(0.509-4.838)$ \\
\hline
\end{tabular}

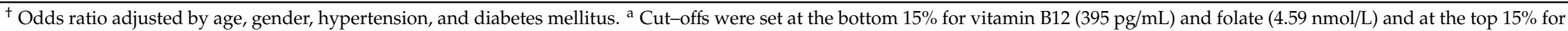
homocysteine $(12.68 \mathrm{umol} / \mathrm{L})$ for both osteoporosis patients and controls. 
Table 5. Stratified analysis of OVCF incidence by interactions with age, hypertension, diabetes mellitus, and levels of vitamin B12, folate, and homocysteine.

\begin{tabular}{|c|c|c|c|c|c|c|c|c|}
\hline \multirow{2}{*}{ Variables $^{\dagger}$} & \multicolumn{2}{|c|}{ CD320 rs9426 CC vs. CT+TT } & \multicolumn{2}{|c|}{ TCN2 rs10418 CC vs. CT+TT } & \multicolumn{2}{|c|}{ SLC19A1 rs1051296 GG vs. GT+TT } & \multicolumn{2}{|c|}{ SLC19A2 rs16862199 CC vs. CT+TT } \\
\hline & AOR $(95 \% \mathrm{CI})$ & AOR $(95 \% \mathrm{CI})$ & AOR $(95 \% \mathrm{CI})$ & AOR $(95 \% \mathrm{CI})$ & AOR $(95 \% \mathrm{CI})$ & AOR $(95 \% \mathrm{CI})$ & AOR $(95 \% \mathrm{CI})$ & AOR $(95 \% \mathrm{CI})$ \\
\hline \multicolumn{9}{|l|}{ Age } \\
\hline$<69$ & 1.000 (reference) & $0.383(0.133-1.104)$ & 1.000 (reference) & $1.257(0.479-3.301)$ & 1.000 (reference) & $\begin{array}{c}3.782 \\
(1.210-11.817)\end{array}$ & 1.000 (reference) & $1.257(0.479-3.301)$ \\
\hline $\begin{array}{l}\geq 69 \\
\text { erten }\end{array}$ & $0.642(0.334-1.234)$ & $2.101(0.907-4.868)$ & $1.057(0.557-2.004)$ & $1.489(0.638-3.473)$ & $5.132(1.468-17.939)$ & $2.578(0.810-8.208)$ & $1.057(0.557-2.004)$ & $1.489(0.638-3.473)$ \\
\hline No & 1.000 (reference) & 1. & 1. & $2.125(0.829-5.448)$ & & & & \\
\hline Yes & 0.911 & 0.96 & 0.900 & 7) & 0.87 & 67) & 0.900 & 0.96 \\
\hline \multicolumn{9}{|l|}{$\begin{array}{l}\text { Diabetes } \\
\text { mellitus }\end{array}$} \\
\hline No & 1.000 (reference) & 1.270 & $1.000(\mathrm{ref}$ & $1.781(0.8$ & $1.000(\mathrm{r}$ & $1.257(0.6$ & 1.000( & $1.781(0.881-3.600)$ \\
\hline Yes & $0.851(0.310-2.340)$ & $1.273(0.301$ & $1.301(0.486-3.477)$ & 1) & $1.492(0.368-6.038)$ & $0.847(0.261-2.744)$ & $1.301(0.486-3.477)$ & $0.543(0.113-2.621)$ \\
\hline \multicolumn{9}{|l|}{ Vitamin B12 ${ }^{\mathrm{a}}$} \\
\hline$>395 \mathrm{pg} / \mathrm{mL}$ & 1.000 (reference) & $1.242(0.653-2.362)$ & 1.000 (reference) & $1.259(0.646-2.454)$ & 1.000 (reference) & $1.064(0.561-2.018)$ & 1.000 (reference) & $1.259(0.646-2.454)$ \\
\hline $\begin{array}{c}\leq 395 \mathrm{pg} / \mathrm{mL} \\
\text { Folate }^{\mathrm{a}}\end{array}$ & $0.845(0.215-3.313)$ & $1.524(0.129-18.010)$ & $0.469(0.098-2.255)$ & $2.495(0.331-18.782)$ & N/A & $0.784(0.201-3.056)$ & $0.469(0.098-2.255)$ & $2.495(0.331-18.782)$ \\
\hline$>4.59 \mathrm{nmol} / \mathrm{L}$ & 1.000 (reference) & $1.097(0.520-2.315)$ & $1.000(\mathrm{r}$ & $1.575(0.740-3.351)$ & 1.000 (ref & $1.028(0.498-2.120)$ & 1.000 & $1.575(0.740-3.351)$ \\
\hline$\leq 4.59 \mathrm{nmol} / \mathrm{L}$ & $3.219(1.418-7.307)$ & 7.307 (1.975-27.033) & $4.290(1.911-9.629)$ & 3.085 (0.914-10.411) & $2.022(0.469-8.730)$ & $3.589(1.440-8.950)$ & $4.290(1.911-9.629)$ & $3.085(0.914-10.411)$ \\
\hline \multicolumn{9}{|l|}{ Homocysteine $^{\mathrm{a}}$} \\
\hline$<12.68 \mu \mathrm{mol} / \mathrm{L}$ & 1.000( & 0.931 & 1.000 & 1.8 & 1.00 & $1.129(0.57$ & 1.000 & $1.810(0.898-3.649)$ \\
\hline$\geq 12.68 \mu \mathrm{mol} / \mathrm{L}$ & $1.020(0.335-3.103)$ & $5.760(1.480-22.417)$ & $2.911(1.100-7.704)$ & $0.861(0.168-4.425)$ & $3.100(0.492-19.542)$ & $1.286(0.434-3.807)$ & $2.911(1.100-7.704)$ & $0.861(0.168-4.425)$ \\
\hline
\end{tabular}

+ Odds ratio adjusted by age, gender, hypertension, and diabetes mellitus. OVCF, osteoporotic vertebral compression fracture. ${ }^{\text {a }}$ Cut-offs were set at the bottom $15 \%$ for vitamin B12 (395 $\mathrm{pg} / \mathrm{mL})$ and folate $(4.59 \mathrm{nmol} / \mathrm{L})$ and at the top $15 \%$ for homocysteine $(12.68 \mathrm{umol} / \mathrm{L})$ for both osteoporosis patients and controls. 


\section{Discussion}

Emerging evidence suggests that B-vitamins, in particular vitamin B1, B12 (cobalamin) and B9 (folate) exert bone-protective effects, whereas homocysteine has a detrimental effect on bone health [2-7]. It is also known that folate, vitamin B12, vitamin B6, and vitamin B2 (riboflavin) are involved in the homocysteine metabolism [20]. Therefore, folate and vitamin B12 deficiencies can cause increased serum levels of homocysteine contributing to osteoporosis and osteoporotic bone fractures. Cobalamin is first bound to cobalamin transport protein (TC II, encoded by TCN2 gene) and TC II-cobalamin complex then enters the cells via its interaction with TC II receptor (encoded by $C D 320$ gene) on the cell surface $[15,19,21]$. Transport of thiamine and folate into cells can occur via thiamine carrier 1 (TC1) (encoded by SLC19A2) and reduced folate carrier (encoded by SLC19A1), respectively [18]. B vitamins status can be associated mainly with SNPs in genes directly involved in vitamin absorption/uptake (CD320) or transport (TCN2, SLC19A1, SLC19A2) and SNPs in these genes may have a detrimental effect on bone health by individual action as vitamins and their action on influencing homocysteine concentration [2-7].

In the present study, we explored possible associations between SNPs located in the 3'-UTR of the CD320, TCN2, SLC19A1, and SLC19A2 genes and osteoporosis and OVCFs in 301 postmenopausal women. The main findings from this study are as follows:(1) Individuals with CD320 CT+TT genotype and high homocysteine concentrations had a significantly increased risk of osteoporosis and OVCF; (2) the CD320 C-TCN2 T-SLC19A1 T-SLC19A2 C and CD320 T-TCN2 C-SLC19A1 G-SLC19A2 $\mathrm{C}$ allele combinations was significantly associated with an increased risk of osteoporosis. Our patients with osteoporosis, particularly those patients with OVCFs, exhibit higher blood glucose levels, decreased folate levels, and lower BMIs compared to control subjects. These findings are in accordance with results from previous osteoporosis studies. The risk for osteoporosis and osteoporotic fractures is significantly associated with both type 1 and type 2 diabetes [22-24]. It has also been reported that low folate levels and high homocysteine levels in serum are significantly associated with osteoporotic fractures [25]. Low BMI is an additional important risk factor for low bone mass and increased risk of osteoporotic fractures [26,27]. However, homocysteine levels did not exhibit a significant association with osteoporosis or OVCF in the current study.

A stratified analysis of osteoporosis and OVCF incidence revealed a significantly increased risk for both osteoporosis $(\mathrm{AOR}=5.019)$ and OVCF $(\mathrm{AOR}=5.760)$ in patients with high homocysteine levels $(\geq 12.68 \mu \mathrm{mol} / \mathrm{L})$ and genotype CD320 CT+TT versus individuals with normal homocysteine levels and genotype CD320 CC. These results highlight the relationship of genotypes with the incidence of osteoporosis and OVCF in individuals with high homocysteine levels; notably, there was no significant difference in homocysteine concentrations between the control and osteoporosis groups within this study (Table 1). Although a dominant model failed to identify statistical differences in the stratified analysis, a recessive model did identify an increased risk for osteoporosis and OVCF in specific subsets of individuals with the recessive genotype (Tables 4 and 5).

Overall, the results of the present study indicate that the incidence of osteoporosis and OVCF is significantly increased in a subset of patients who are carrying genotype CD320 CT+TT and have high homocysteine levels. Stone et al. described that the SNP at the binding site of miR-136 is significantly associated with total homocysteine level and methylmalonic acid level [28]. The serum homocysteine concentration in normal individuals ranges from 5 to $12 \mu \mathrm{mol} / \mathrm{L}$. Mild hyperhomocysteinemia is defined as a homocysteine concentration between 12-16 $\mu \mathrm{mol} / \mathrm{L}$ [29]. In the present study, the cut-off set at the top $15 \%$, which equated to $12.68 \mu \mathrm{mol} / \mathrm{L}$, was in accordance with this established range for elevated homocysteine levels. A nationally representative, cross-sectional survey revealed a relationship between elevated homocysteine concentrations and both bone turnover markers and total body and lumbar spine BMD in women $\geq 50$ years of age [30]. Additionally, cross-sectional data from the BPROOF study and from two Rotterdam Study cohorts have reported a significant inverse association between elevated homocysteine levels in women and both bone ultrasound parameters indicative of lower bone quality and with lower BMD. It has been hypothesized that homocysteine 
might impede collagen cross-link formation within bone, thereby weakening bone strength in a manner independent of BMD [31]. Yang et al. reported that mildly elevated serum homocysteine levels $(>13 \mathrm{nmol} / \mathrm{mL})$ in the general population are associated with increased risk of vertebral and hip fractures that is independent of conventional risk factors [32]. Methylation of DNA plays an important role in the regulation of gene expression, and the conversion of methionine to homocysteine involves the removal of a methyl group that could be subsequently donated to DNA. High homocysteine levels could dampen this conversion, thereby reducing DNA methylation activity and altering gene expression, which could influence expression of the CD320 gene.

Allele-allelic combination analysis revealed that the various combinations were significantly associated with osteoporosis and OVCF risk, suggesting putative gene-gene interactions. Among them, the combination of CD320 C-TCN2 T-SLC19A1 G-SLC19A2 T showed the strongest association with osteoporosis risk. Our analyses therefore suggest that the allelic combinations of CD320, TCN2, $S L C 19 A 1$, and SLC19A2 genes could play a role in the pathogenesis of osteoporosis and OVCF.

Currently, there are no genetic studies in 3'-UTR polymorphisms associating osteoporosis with folate and vitamin B12, and only a few clinical studies have evaluated the effects of folic acid and vitamin B12 on plasma homocysteine levels and bone health. In the Hordaland Homocysteine Study, folate was linked to BMD and a reduced fracture risk, but there was limited evidence to support a direct effect of folate on bone health [33,34]. In the current study, we identified significant differences in folate and vitamin B12 levels between the control and osteoporosis groups, although the levels of folate and vitamin B12 were within the normal range for all groups. Even in the stratified analysis, the bottom $15 \%$ of folate and vitamin B12 levels were within the normal range. Therefore, we did not draw substantial findings from these genetic analyses.

We used the LDlink (https://ldlink.nci.nih.gov/) to find out the SNPs linked to each SNPs and identify other SNPs in the linkage disequilibrium (LD) relationship to the SNPS analyzed in the present study. According to the LD link tool (LD proxy), there was no tightly linked variants associated with TCN2 rs10418 C > T and SLC19A2 rs16862199 C > T. By contrast, the CD320 rs9426 C > T and SLC19A1 rs1051296G > T were reported to be tightly linked with CD320 rs2336573 variant and SLC19A2 rs12659, respectively $[35,36]$.

There are several limitations of this study. First, the study included only Korean postmenopausal women, and our results cannot be generalized to other racial or ethnic groups because SNPs and allele combinations vary among ethnic groups. Second, this was a hospital-based case-control study, and the sample size was relatively small. Thus, the present results should be replicated and validated in larger studies that include diverse ethnic groups and men. Third, we could not conclusively exclude other potential confounding variables, such as exposure to different environmental factors (e.g., smoking, nutrition, calcium and vitamin intake), and this study was not a genome-wide association study; therefore, the additional genetic risk factors affecting osteoporosis and OVCF are unclear. Fourth, we did not identify the miRNAs of the target genes and did not perform in vitro studies. Lastly, we should consider the possible changes of analyzed genes due to change in miRNA action because we investigated SNPs located in 3'-UTR of B vitamin-related genes. Genetic variation in the 3'-UTR can affect gene expression by interfering with miRNA binding [12,37,38]. Polymorphisms residing within the miRNA-binding site of the target genes may have their own disease onset effect, but changes in the miRNA binding efficiency also has to be considered [23,24]. Thus, our study does not rule out the possibility that change in miRNA action could influence our results.

\section{Conclusions}

We have identified associations between four B vitamin-related SNPs in 3'-UTR, namely CD320C $>$ T (rs9426), TCN2C $>$ T ( rs10418), SLC19A1G $>$ T (rs1051296), and SLC19A2C > T (rs16862199), and the occurrence of osteoporosis and OVCF in Korean postmenopausal women. Our findings suggest that SNPs in the miRNA binding site within the 3'-UTR of the CD320 gene may contribute to osteoporosis and OVCF occurrences in some individuals with high homocysteine level. Although these 
findings do not broadly address the complex pathogenesis of osteoporosis, the data described here could contribute to the available pool of SNP variants needed for the individual assessment of osteoporosis and OVCF risk.

Supplementary Materials: The following are available online at http://www.mdpi.com/2073-4425/11/6/612/s1. Table S1: Stratified effects in the 3'-UTR polymorphisms of CD320, TCN2, SLC19A1, and SLC19A2 genes on osteoporosis risk; Table S2: Stratified effects in the 3'-UTR polymorphisms of CD320, TCN2, SLC19A1, and SLC19A2 genes on incidence of OVCF.

Author Contributions: Conceptualization, N.K.K. and I.-B.H.; Data curation, H.J.A.; U.Y.C. and S.S.; Investigation, K.-T.K.; Methodology, H.S.P.; Resources, N.K.K. and I.-B.H.; Writing-original draft, T.-K.A. and J.O.K.; Writing-review \& editing, T.-K.A., N.K.K. and I.-B.H. All authors have read and agreed to the published version of the manuscript.

Funding: This study was supported by a grant of the Korea Healthcare Technology R\&D Project, Ministry of Health and Welfare, Republic of Korea (HR16C0002, HI16C0106, HI20C0579, H18C1999) and National Research Foundation of Korea (NRF 2020R1A2C4001870).

Conflicts of Interest: The authors declare no conflict of interest.

\section{References}

1. Saito, M.; Marumo, K. The effects of homocysteine on the skeleton. Curr. Osteoporos. Rep. 2018, 16, 554-560. [CrossRef] [PubMed]

2. Ma, Q.; Liang, M.; Wang, Y.; Ding, N.; Wu, Y.; Duan, L.; Yu, T.; Lu, Y.; Xu, J.; Kang, F. Non-coenzyme role of vitamin B1 in RANKL-induced osteoclastogenesis and ovariectomy induced osteoporosis. J. Cell. Biochem. 2020. [CrossRef] [PubMed]

3. Bucciarelli, P.; Martini, G.; Martinelli, I.; Ceccarelli, E.; Gennari, L.; Bader, R.; Valenti, R.; Franci, B.; Nuti, R.; Mannucci, P.M. The relationship between plasma homocysteine levels and bone mineral density in post-menopausal women. Eur. J. Intern. Med. 2010, 21, 301-305. [CrossRef] [PubMed]

4. McLean, R.R.; Jacques, P.F.; Selhub, J.; Fredman, L.; Tucker, K.L.; Samelson, E.J.; Kiel, D.P.; Cupples, L.A.; Hannan, M.T. Plasma B vitamins, homocysteine, and their relation with bone loss and hip fracture in elderly men and women. J. Clin. Endocrinol. Metab. 2008, 93, 2206-2212. [CrossRef]

5. Baines, M.; Kredan, M.-B.; Usher, J.; Davison, A.; Higgins, G.; Taylor, W.; West, C.; Fraser, W.D.; Ranganath, L.R. The association of homocysteine and its determinants MTHFR genotype, folate, vitamin B12 and vitamin B6 with bone mineral density in postmenopausal British women. Bone 2007, 40, 730-736. [CrossRef]

6. Morris, M.S.; Jacques, P.F.; Selhub, J. Relation between homocysteine and B-vitamin status indicators and bone mineral density in older Americans. Bone 2005, 37, 234-242. [CrossRef]

7. Dai, Z.; Koh, W.-P. B-vitamins and bone health-a review of the current evidence. Nutrients 2015, 7, 3322-3346. [CrossRef]

8. Ahmad, I.; Jafar, T.; Mahdi, F.; Arshad, M.; Das, S.K.; Waliullah, S.; Mahdi, A.A. Association of Vitamin D Receptor (FokI and BsmI) Gene Polymorphism with Bone Mineral Density and Their Effect on 25-Hydroxyvitamin D Level in North Indian Postmenopausal Women with Osteoporosis. Indian J. Clin. Biochem. 2018, 33, 429-437. [CrossRef]

9. Li, Y.; Xi, B.; Li, K.; Wang, C. Association between vitamin D receptor gene polymorphisms and bone mineral density in Chinese women. Mol. Biol. Rep. 2012, 39, 5709-5717. [CrossRef]

10. Abrahamsen, B.; Madsen, J.S.; Tofteng, C.L.; Stilgren, L.; Bladbjerg, E.M.; Kristensen, S.R.; Brixen, K.; Mosekilde, L. Are effects of MTHFR (C677T) genotype on BMD confined to women with low folate and riboflavin intake? Analysis of food records from the Danish osteoporosis prevention study. Bone 2005, 36, 577-583. [CrossRef]

11. Lei, S.-F.; Papasian, C.J.; Deng, H.-W. Polymorphisms in Predicted miRNA Binding Sites and Osteoporosis. J. Bone Min. Res. 2011, 26, 72-78. [CrossRef] [PubMed]

12. Ahn, T.-K.; Kim, J.O.; Kim, H.W.; Park, H.S.; Shim, J.H.; Ropper, A.E.; Han, I.B.; Kim, N.K. 3'-UTR Polymorphisms of MTHFR and TS Associated with Osteoporotic Vertebral Compression Fracture Susceptibility in Postmenopausal Women. Int. J. Mol. Sci. 2018, 19, 824. [CrossRef] [PubMed]

13. McLean, R.R.; Hannan, M.T. B vitamins, homocysteine, and bone disease: Epidemiology and pathophysiology. Curr. Osteoporos. Rep. 2007, 5, 112-119. [CrossRef] [PubMed] 
14. Lubec, B.; Fang-Kircher, S.; Lubec, T.; Blom, H.J.; Boers, G.H. Evidence for McKusick's hypothesis of deficient collagen cross-linking in patients with homocystinuria. Biochim. Biophys. Acta 1996, 1315, 159-162. [CrossRef]

15. Fedosov, S.N. Physiological and molecular aspects of cobalamin transport. In Water Soluble Vitamins; Springer: Berlin/Heidelberg, Germany, 2012; pp. 347-367.

16. Matteini, A.M.; Walston, J.D.; Bandeen-Roche, K.; Arking, D.E.; Allen, R.H.; Fried, L.P.; Chakravarti, A.; Stabler, S.P.; Fallin, M.D. Transcobalamin-II variants, decreased vitamin B12 availability and increased risk of frailty. J. Nutr. Health Aging 2010, 14, 73-77. [CrossRef] [PubMed]

17. Quadros, E.V.; Sequeira, J.M. Cellular uptake of cobalamin: Transcobalamin and the TCblR/CD320 receptor. Biochimie 2013, 95, 1008-1018. [CrossRef] [PubMed]

18. Genant, H.K.; Wu, C.Y.; Van Kuijk, C.; Nevitt, M.C. Vertebral fracture assessment using a semiquantitative technique. J. Bone Miner. Res. 1993, 8, 1137-1148. [CrossRef]

19. Ryu, C.S.; Sakong, J.H.; Ahn, E.H.; Kim, J.O.; Ko, D.; Kim, J.H.; Lee, W.S.; Kim, N.K. Association study of the three functional polymorphisms (TAS2R46G $>$ A, OR4C16G $>$ A, and OR4X1A $>$ T) with recurrent pregnancy loss. Genes Genom. 2019, 41, 61-70. [CrossRef]

20. Fratoni, V.; Brandi, M.L. B vitamins, homocysteine and bone health. Nutrients 2015, 7, 2176-2192. [CrossRef]

21. Quadros, E.V.; Nakayama, Y.; Sequeira, J.M. Targeted delivery of saporin toxin by monoclonal antibody to the transcobalamin receptor, TCblR/CD320. Mol. Cancer Ther. 2010, 9, 3033-3040. [CrossRef]

22. Giangregorio, L.M.; Leslie, W.D.; Lix, L.M.; Johansson, H.; Oden, A.; McCloskey, E.; Kanis, J.A. FRAX underestimates fracture risk in patients with diabetes. J. Bone Miner. Res. 2012, 27, 301-308. [CrossRef] [PubMed]

23. Leslie, W.D.; Rubin, M.R.; Schwartz, A.V.; Kanis, J.A. Type 2 diabetes and bone. J. Bone Miner. Res. 2012, 27, 2231-2237. [CrossRef] [PubMed]

24. Kurra, S.; Siris, E. Diabetes and bone health: The relationship between diabetes and osteoporosis-associated fractures. Diabetes/Metab. Res. Rev. 2011, 27, 430-435. [CrossRef] [PubMed]

25. Gjesdal, C.G.; Vollset, S.E.; Ueland, P.M.; Refsum, H.; Drevon, C.A.; Gjessing, H.K.; Tell, G.S. Plasma total homocysteine level and bone mineral density: The Hordaland Homocysteine Study. Arch. Intern. Med. 2006, 166, 88-94. [CrossRef]

26. Barrera, G.; Bunout, D.; Gattás, V.; de la Maza, M.P.; Leiva, L.; Hirsch, S. A high body mass index protects against femoral neck osteoporosis in healthy elderly subjects. Nutrition 2004, 20, 769-771. [CrossRef]

27. Ravn, P.; Cizza, G.; Bjarnason, N.H.; Thompson, D.; Daley, M.; Wasnich, R.D.; McClung, M.; Hosking, D.; Yates, A.J.; Christiansen, C. Low body mass index is an important risk factor for low bone mass and increased bone loss in early postmenopausal women. J. Bone Miner. Res. 1999, 14, 1622-1627. [CrossRef]

28. Stone, N.; Pangilinan, F.; Molloy, A.M.; Shane, B.; Scott, J.M.; Ueland, P.M.; Mills, J.L.; Kirke, P.N.; Sethupathy, P.; Brody, L.C. Bioinformatic and genetic association analysis of microRNA target sites in one-carbon metabolism genes. PLoS ONE 2011, 6. [CrossRef]

29. Perna, A.F.; Ingrosso, D.; Violetti, E.; Luciano, M.G.; Sepe, I.; Lanza, D.; Capasso, R.; Ascione, E.; Raiola, I.; Lombardi, C. Progress in Uremic Toxin Research: Hyperhomocysteinemia in Uremia-A Red Flag in a Disrupted Circuit. In Proceedings of the Seminars in Dialysis; Wiley Online Library: Hoboken, NJ, USA, 2009; Volume 22, pp. 351-356.

30. Bailey, R.L.; Looker, A.C.; Lu, Z.; Fan, R.; Eicher-Miller, H.A.; Fakhouri, T.H.; Gahche, J.J.; Weaver, C.M.; Mills, J.L. B-vitamin status and bone mineral density and risk of lumbar osteoporosis in older females in the United States. Am. J. Clin. Nutr. 2015, 102, 687-694. [CrossRef]

31. Enneman, A.W.; Swart, K.M.; Zillikens, M.C.; van Dijk, S.C.; van Wijngaarden, J.P.; Brouwer-Brolsma, E.M.; Dhonukshe-Rutten, R.A.; Hofman, A.; Rivadeneira, F.; van der Cammen, T.J. The association between plasma homocysteine levels and bone quality and bone mineral density parameters in older persons. Bone 2014, 63, 141-146. [CrossRef]

32. Yang, J.; Hu, X.; Zhang, Q.; Cao, H.; Wang, J.; Liu, B. Homocysteine level and risk of fracture: A meta-analysis and systematic review. Bone 2012, 51, 376-382. [CrossRef]

33. Cagnacci, A.; Bagni, B.; Zini, A.; Cannoletta, M.; Generali, M.; Volpe, A. Relation of folates, vitamin B12 and homocysteine to vertebral bone mineral density change in postmenopausal women. A five-year longitudinal evaluation. Bone 2008, 42, 314-320. [CrossRef] [PubMed] 
34. Gjesdal, C.G.; Vollset, S.E.; Ueland, P.M.; Refsum, H.; Meyer, H.E.; Tell, G.S. Plasma homocysteine, folate, and vitamin B12 and the risk of hip fracture: The Hordaland Homocysteine Study. J. Bone Miner. Res. 2007, 22, 747-756. [CrossRef] [PubMed]

35. Durie, B.G.M.; Van Ness, B.; Ramos, C.; Stephens, O.; Haznadar, M.; Hoering, A.; Haessler, J.; Katz, M.S.; Mundy, G.R.; Kyle, R.A. Genetic polymorphisms of EPHX1, Gsk3 $\beta$, TNFSF8 and myeloma cell DKK-1 expression linked to bone disease in myeloma. Leukemia 2009, 23, 1913-1919. [CrossRef]

36. Kurnat-Thoma, E.L.; Pangilinan, F.; Matteini, A.M.; Wong, B.; Pepper, G.A.; Stabler, S.P.; Guralnik, J.M.; Brody, L.C. Association of transcobalamin II (TCN2) and transcobalamin II-receptor (TCblR) genetic variations with cobalamin deficiency parameters in elderly women. Biol. Res. Nurs. 2015, 17, 444-454. [CrossRef] [PubMed]

37. An, H.J.; Kim, J.H.; Ahn, E.H.; Kim, Y.R.; Kim, J.O.; Park, H.S.; Ryu, C.S.; Kim, E.-G.; Cho, S.H.; Lee, W.S. 3'-UTR Polymorphisms in the Vascular Endothelial Growth Factor Gene (VEGF) Contribute to Susceptibility to Recurrent Pregnancy Loss (RPL). Int. J. Mol. Sci. 2019, 20, 3319. [CrossRef] [PubMed]

38. Kim, J.O.; Park, H.S.; Ryu, C.S.; Shin, J.-W.; Kim, J.; Oh, S.H.; Kim, O.J.; Kim, N.K. Interplay between 3'-UTR polymorphisms in the methylenetetrahydrofolate reductase (MTHFR) gene and the risk of ischemic stroke. Sci. Rep. 2017, 7, 1-10. [CrossRef] [PubMed]

(C) 2020 by the authors. Licensee MDPI, Basel, Switzerland. This article is an open access article distributed under the terms and conditions of the Creative Commons Attribution (CC BY) license (http://creativecommons.org/licenses/by/4.0/). 